\title{
LA AGROENERGÍA: SUS DIMENSIONES SOCIECONÓMICAS. ENTRE LAS CRISIS ALIMENTARIA, CLIMÁTICA Y DE CAPITAL
}

Francois Houtart

\section{Resumen}

A pesar de las expectativas de los poderosos intereses económicos y políticos cifrados en los agrocarburantes, éstos no parecen ser ni una solución a la crisis energética, ni mucho menos a la climática; más bien se revelan como una seria amenaza para el medio ambiente, en particular de los países del Sur, un peligroso factor del agravamiento de la crisis alimentaria, pero principalmente, una salida muy rentable para la crisis del capital y con unos colosales costos sociales y políticos concretamente en los países subdesarrollados.

François Houtart

\section{El modelo agrícola a la base de los agrocarburantes}

Como la agroenergía se desarrolla hoy en el marco de la lógica del capitalismo, no es inútil llamar la atención sobre las condiciones generales de la producción agrícola como factor de acumulación. La producción de alimentos es evidentemente esencial para la supervivencia de la humanidad. Ahora bien, algunos emiten hoy serios temores sobre la posibilidad de alimentar el conjunto de los seres humanos en un futuro de mediano plazo. Sin embargo, la FAO es formal: la tierra puede nutrir a 12 mil millones de personas. Hemos ya abordado este problema en 1963 con Michel Cepede, delegado de Francia ante la FAO, y Linus Grond, secretario general de FERES, la Federación Internacional de Institutos de Investigaciones socioreligiosas.

Las proyecciones demográficas prevén una población de 9 a 10 mil millones de habitantes para el año 2050, con una estabilización de las cifras a partir de este periodo.¿Cómo entonces se explica que de $6 \mathrm{mil}$ millones de personas hoy más de 800 millones sufran de hambre, y que cada cuatro segundos un ser humano muera por esta razón (Ziegler,

* Fundador del Centro Tricontinental Louvaine La neuve. 
2005) $)^{1}$. Sin prejuzgar ciertas causas naturales, se puede afirmar que el factor dominante es el orden económico-político. Esto es precisamente lo que dice el informe Fred Magdoff, profesor de agronomía de la Universidad de Vermont en los Estados Unidos: "La malnutrición crónica y la inseguridad alimentaria son esencialmente causadas por la pobreza y no por la falta de producción alimentaria"2. Plantear estas cuestiones reviste un sentido importante para el problema de los agrocarburantes, a la vez porque se volverán inevitablemente concurrentes con la producción alimentaria y porque se inscriben en la lógica dominante de la actividad agrícola.

¿Cuál es por consiguiente el modelo de economía agraria promovido por el sistema económico contemporáneo? El argumento clave es precisamente el de la alimentación mundial. Frente a la dimensión del fenómeno del hambre, el razonamiento consiste en decir que sólo una producción creciente podrá salir al paso de las necesidades. Pues bien, siempre según el mismo sistema de pensamiento, la pequeña unidad campesina se muestra bien ineficaz desde este punto de vista. Es necesario promover una agricultura capaz de producir masivamente. Esto es tanto más necesario, que los hábitos alimentarios se transforman y se uniformizan bajo el golpe de la mundialización, que éstos no sean solamente los alimentos que proceden de la agricultura, sino los industriales para las empresas farmacéuticas o cosméticas y que explosiona hoy la demanda de los agrocarburantes. ¿Cómo pues responder a la doble exigencia de alimentar la humanidad y de producir materias primas y combustibles verdes?

La respuesta es relativamente simple en el marco de esta lógica: es preciso extender el monocultivo, lo que permite reducir los costos por el juego de una economía de escala y de disminuir la utilización de mano de obra, gracias a las posibilidades de la mecanización. Esto exige concentrar la propiedad de la tierra y proceder a contra-reformas agrarias. Aumentar la productividad es también una necesidad, de ahí extender los insu-

1 Jean Ziegler, reportero especial de las Naciones Unidas sobre la pobreza en el mundo, L'impire du Chaos, Fayard, Paris, 2005.

2 A precaroius Existence the Fate of Billions, en Samir Amin, Poverty, Pauperization and Capital Accumulation, Monthly Review, octobre 2003. 
mos que enriquezcan los suelos, la aplicación de productos químicos destructores de los parásitos y la utilización de las técnicas de las OGM (Organismos Genéticamente Modificados), que vuelvan a las plantas más resistentes a las contingencias naturales o artificiales. Por otro lado, es también ventajoso universalizar ciertas razas de ganados, gruesos, pequeños o medianos, porque eso facilita sus mercantilización. Como la mano de obra agrícola es abundante, puede seguir siendo poco costosa. Es la ley del mercado. El tratamiento industrial de las producciones agrícolas y de cría de ganado permite la racionalización del tiempo de las manipulaciones, y su distribución puede entonces entrar en los circuitos internacionales, con las mismas ventajas que los productos industriales.

Todo esto permite crear progresivamente un mercado agrícola mundial colocando sus precios sobre los más performantes y contribuye así a la racionalización de la economía agraria. Se trata de una verdadera revolución verde, igual a la revolución industrial. Para realizar tareas tan hercúleas, es decir para poder nutrir de 9 a 10 mil millones de individuos en el horizonte de la mitad del siglo XXI, sólo las empresas de grandes dimensiones y capaces de transcender las fronteras de los
Estados, son capaces de responder a la tarea y de enfrentar el desafío. He ahí lo esencial de la posición del modelo capitalista. A partir de estas constataciones, el discurso se vuelve moralizador y casi mesiánico; sobre todo, cuando aborda el tema de los agrocarburantes. El carácter menos contaminador de este tipo de combustibles en comparación con la energía de origen fósil y por consiguiente menos destructivo del clima, permite, en efecto, de calificarlos de biocarburantes, en el sentido simbólico de la palabra.

Un tal lenguaje no carece de lógi$\mathrm{ca}$, pero las zonas oscuras son considerables. En primer lugar, como en todo razonamiento económico capitalista, las externalidades no son tomadas en cuenta. Hasta tal punto que las ganancias sobre las inversiones no están afectadas por la polución de los suelos, del agua y de la atmósfera, o más aún del costo colectivo de la urbanización salvaje o por la resistencia de los campesinos y desplazados, todo un conjunto de factores queda ignorado. Los mercados agrícolas diferenciados responden a las exigencias de la soberanía alimentaria o a los hábitos culturales, o incluso a la propiedad colectiva de tierra de cultivo para las comunidades campesinas o indígenas (ejidos en México, tierras colectivas en Vietnam 
o en China, propiedad comunal en Sri Lanka) constituyen herejías para una economía de mercado capitalista. Deben pues dar lugar a soluciones más racionales y económicamente más eficaces.

Es ahí donde está el problema: eficaz ¿en función de qué? ¿El equilibrio ecológico del planeta o el bienestar de los campesinos, que, recordemos, representan todavía casi la mitad de la población mundial?, ¿la durabilidad de la producción agrícola, o finalmente la acumulación del capital, que no sólo de medio se convierte en fin y se cierra así en el corto y mediano plazo? Esta última preocupación borra de hecho del panorama, todo lo que no contribuye al provecho y a sus componentes inseparables: mercantilización de todas las actividades humanas (reducidas a su valor de cambio), rentabilidad financiera obligatoria, competitividad sin piedad, espíritu de emprendimiento ligado exclusivamente a la propiedad privada de los bienes de producción, centralidad del dinero convertido el mismo en una mercancía.

Se trata realmente de una perversión de lo que se podría llamar las constantes de la economía. Es verdad que ninguna de estas constantes puede ser descuidada: el mercado es un buen regulador de la oferta y de la demanda, cuando la relación social entre las partes es equitable; una rentabilidad que incluya todos los parámetros del bienestar humano permite evitar los despilfarros; la competitividad conjura los monopolios paralizantes y refuerza la eficacia de los procesos de producción. Finalmente, el espíritu emprendedor debe poder ser propio de todos los seres humanos inscritos en el marco de una apropiación socializada de los bienes de producción (lo que no significa ni una simple ampliación del accionariado ni necesariamente la estatización de todos los sectores). En cuanto a la utilización de un instrumento universal del intercambio de bienes y de servicios como la moneda, es un medio útil de transacción (sin ser por ello el único).

Todo esto significa que los elementos constitutivos de la actividad económica están sometidos a un criterio superior, que les da un sentido y les atribuye un lugar en el seno de la estructura del sistema de producción $y$ del intercambio. En un primer modelo, el bien común de la humanidad, es decir la vida física, constituye este criterio. En este momento, es el valor de uso que es privilegiado (es decir, la contribución a la vida y a su reproducción) y se introduce de manera positiva la idea que ciertos sectores no estén asimilados a las mercancías y no puedan ser medidos 
por la pura rentabilidad financiera, ni tampoco sujetos a patentes y a competición monetaria. Se trata por ejemplo, del agua, de las semillas, de los servicios públicos, en particular de la salud y la educación. A cada sociedad compete definir democráticamente las fronteras de estos sectores de bien común, que, de otro lado, pueden evolucionar según el tiempo y el espacio.

En el otro modelo, es la acumulación del capital, considerada como el principal motor del funcionamiento de la economía, que forma el parámetro de base. El discurso identifica entonces los diversos componentes de la economía según este criterio, como si no pudieran existir de otra manera. De ahí el dogma del mercado, desembocando en lo que se llama "el pensamiento único" y la fuerza de la convicción de aquellos que pretenden que no hay alternativas. Mejor aún, el sistema es naturalizado, negándole así todo carácter de construcción social. Y sin embargo, las desigualdades sociales expresadas por el famoso gráfico del PNUD en forma de copa de champán ilustran el reparto de las ganancias en el mundo (los $20 \%$ más ricos absorben el $82,4 \%$ de las riquezas mundiales y los $20 \%$ más pobres comparten el 1,6\%).Y eso para indicar que se trata de una minoría que, en el mundo entero, monopoliza el consumo y el poder de decisión sobre la economía, mientras que la "masas inútiles" son reducidas a la supervivencia o a la miseria. No obstante, la producción de la riqueza en el mundo podría permitir a todos no sólo gozar de la vida sino también ser actores capaces de contribuir al bienestar de todos.

¿Cómo esto se traduce en el ámbito de la organización de la economía agraria? Samir Amin resume muy bien la cuestión: "La agricultura capitalista, representada por una clase de nuevos campesinos ricos, es decir latifundistas modernizados, o por propiedades explotadas por las transnacionales de la agroempresa, se dispone a dar el asalto a la agricultura campesina. Ya ha recibido la autorización de la OMC en Doha. La producción es compartida entre dos sectores, cuya naturaleza económica y social es perfectamente distinta. La agricultura capitalista, conducida por el principio de la rentabilidad del capital, localizada casi exclusivamente en América del Norte, en Europa, en el cono sur de América latina y en Australia, no emplea más que algunas decenas de millones de agricultores, que no son ya verdaderamente "campesinos". Pero su productividad, función de la motorización y mecanización... y de la superficie 
disponible, evoluciona entre $10.000 \mathrm{y}$ 20.000 quintales de equivalentes cereales por trabajador y por año. Las agriculturas campesinas... comparten de su lado entre las que se han beneficiado de la revolución verde (insumos, pesticidas y semillas seleccionadas) aunque poco mecanizadas, cuya producción oscila entre 100 y 500 quintales por trabajador y las que se sitúan antes de esta revolución, cuya producción oscila alrededor de 10 quintales solamente por activo. La distancia entre la productividad de la agricultura mejor equipada y la de la agricultura campesina pobre, que era de 10 a 1 antes de 1940, es hoy de 2.000 a 1" (Amin, 2004) $)^{3}$.

Una tal descripción de la situación actual permite pensar en los mecanismos establecidos para llegar a un tal resultado y que no haremos más que citar: prioridad a la exportación, inaccesibilidad del crédito a los pequeños campesinos, importación de productos alimentarios, deforestaciones masivas, monocultivo $\mathrm{y}$ concentración de la propiedad. Un actor en este ámbito, Blairo Maggi, gobernador del Mato Grosso en Brasil y gran productor de soya, lo afirma sin escrúpulo: "Toda la economía tiende a la concentración, los precios unitarios caen y se necesitan enormes volúmenes para sobrevivir" 4 . Las consecuencias sociales son gigantescas, Abourahmane Ndiaye, de la Universidad de Burdeos, las sintetiza en una expresión chocante: "veinte millones de productores eficaces... disponiendo de una aparato de producción pesado, fabrican $5 \mathrm{mil}$ millones de excluidos. La dimensión creadora de la operación no representa más que una gota de agua ante el océano de las destrucciones que exige". Estos fenómenos han sido admirablemente analizados por autores como Samir Amin, ya citado, Marcel Mazoyer o Jacques Berthelot, en una abundante literatura y en gran parte sintetizada en el número de Alternatives Sud sobre "Question agraire et mondialisation" (vol. IX, 2002, n. 4).

Un nuevo paso ha sido franqueado con la compra de gigantescas concesiones de tierras en los continentes del Sur, en particular África y Asia. Así, una sociedad noruega compra 38.000 hectáreas a un jefe tradicional de Ghana. La sociedad sur-coreana Daewoo, concluye un arriendo por 
99 años de más de un millón de hectáreas en Madagascar, la mitad de las tierras arables del país, lo que James Petras llama "colonización por invitación" 5 . En Laos, ente 2 y 3 millones de hectáreas fueron objeto de similares transacciones. En Camboya, el Haining Group chino obtiene 21.250 hectáreas en la provincia de Kampong Speu. Se señalan en África concesiones atribuidas a firmas de Japón, de China, de los Estados Unidos, para plantaciones alimentarias o de los agrocarburantes. La FAO habla de un nuevo colonialismo.

Revolución verde, reforma agraria, toman en este contexto significaciones muy específicas, destinadas a promover las agroempresas. Los subsidios a los agricultores en periodo de excedentes y que, según Jean Ziegler, alcanzan en 2005 los 349 mil millones de dólares anuales, se convirtieron en gran parte en un medio de hacer pasar el dinero público hacia el privado y de privilegiar a los que entran en la lógica del capitalismo agrario. $Y$ finalmente, el principal, que no ha sido dicho en toda esta cuestión es que la transformación de la agricultura campesina en agricultura productivista es también -y qui- zás sobre todo- una de las nuevas fronteras del capitalismo, que permite hacer frente a las crisis de acumulación de los ámbitos industriales y financieros. De esto se ve una confirmación en Francia, donde, a partir de 2006, con el alza del precio de los cereales, "los inversionistas se interesan súbitamente a las materias primas agrícolas, y la especulación es en parte responsable de la brutalidad de este despegue"6. La demanda de ciertos países emergentes ha permitido liquidar los stocks y la Unión Europea propone suprimir el barbecho en el 2008. El desarrollo de la agroenergía, decidida también para la misma Unión Europea, actúa como un acelerador hasta el punto de que algunos se replantean la cuestión de la alimentación mundial: "antes se administraban los excedentes, ahora va a ser necesario administrar los déficits", escribe la misma Laeticia Claveul (Ibídem). Lo mismo ocurre con el maíz en las Américas o el arroz en Asia.

Es verdad que, como recuerda el profesor Hans Christoph Biswanger, antiguo profesor en la Universidad de St. Gall en Suiza, "el valor añadido generado por la agricultura es siste- 
máticamente inferior al de la industria"7. Las razones de ello son múltiples: una demanda bastante inelástica (son siempre los mismos productos); condiciones de crecimiento de producción más constreñidos, amortizaciones más lentas de la maquinaria utilizada al ritmo de las estaciones, limitaciones concomitantes, fertilizantes y pesticidas peligrosos para la salud y la fertilidad de los suelos; una concurrencia que sólo puede realizarse sobre los precios y débiles márgenes entre los precios y los costos. Como se ve, las diferencias con la industria son considerables, sin hablar de aquellas con las lógicas de los mercados financieros. Entonces ¿cómo puede la agricultura convertirse en una nueva frontera para la acumulación del capital?

Quizás no es más que por un crecimiento de la demanda y a este efecto tres mecanismos son posibles. El primero podría ser la satisfacción cuantitativa de las necesidades en alimentación del inmenso grupo de la población mundial que no come lo que necesita para no pasar hambre. Pero este mecanismo no está al orden del día, pues el modelo de crecimiento privilegia el desarrollo del $20 \%$ de la población mundial, descuidando aquellos que no contribuyen más que de manera marginal a producir un valor agregado y son incapaces de convertirse a corto o mediano plazo en consumidores. La emergencia de países como China o India tiene un fuerte impacto sobre la demanda, ya que se trata de países muy poblados y de $20 \%$ de chinos o de indios, que cada vez consumen más pan y carne, lo cual hace un buen número de clientes, capaces de contribuir al menos indirectamente al agotamiento de los stocks europeos, americanos o asiáticos, y a dar un fuerte empujón a la cría de ganado de la Argentina, del Brasil o de Colombia. Pero por el momento lo esencial de la demanda está satisfecha por estos mismos países emergentes.

La segunda solución consiste en diversificar los productos en función de un cambio cualitativo de la demanda. En el plano alimentario, se trata generalmente de procesos relativamente largos (consumo de carne, por ejemplo) salvo cuando la revolución en los transportes permita una oferta nueva atractiva e innovadora. La llegada a los mercados occidentales de primicias o de productos exó7 H.C. Binswanger, "Impératifs économiques et écologiques d'une politique agricole à long terme”, Horizonts
et Débats, $7^{\circ}$ año, n. 11, 26.03.07. 
ticos transportados por vía aérea ha encontrado salidas en los estratos de ingresos superiores y medios de la sociedad. De ahí el desarrollo casi industrial de ciertas producciones (las flores, por ejemplo) en las regiones de la periferia, mediante costos ecológicos considerables y de condiciones sociales frecuentemente deplorables. Se trata, en efecto, de países que no se cuidan de estos aspectos de la cuestión. Basta que procuren divisas útiles a la retribución del capital local y capaces, gracias a las importaciones, de mantener o incluso de aumentar el modelo de consumo de las clases elevadas y medias. Es necesario añadir, además, que la mayor parte del tiempo son inversiones extranjeras, que operan, no dejando más que un lugar reducido a una burguesía, que sirve de intermediaria (compradora) más influyente en el campo de la política nacional.

La tercera solución es una nueva demanda no alimentaria para diversos tipos de industrias y más precisamente hoy la de los carburantes, que llegan justo para dinamizar los precios de los productos agrícolas y su función de refugio financiero en situación de crisis. Y es aquí, precisamente, que interviene la manera de producir más eficazmente, para que los costos sean reducidos al mínimo y las ganancias maximizadas: es decir, el monocultivo. Este último, en efecto, transforma enormes cantidades de espacios de la agricultura campesina o de busques en producción vegetal única, soya, eucaliptos, palma oleoginosa, caña de azúcar, maíz, trigo, con todas las desventajas ecológicas y sociales de este tipo de actividad agrícola. He ahí por qué la agroenergía se inscribe, también ella, en la nueva frontera del capitalismo, con la doble ventaja de contribuir a la acumulación y de responder aparentemente a las preocupaciones ecológicas, que se han vuelto ineludibles. Pero sería necesario garantizar que los dos objetivos sean compatibles.

\section{Las apuestas económicas y financieras de los agrocarbu- rantes}

El sector de los agrocarburantes ha suscitado un gran interés en los medios financieros. Como lo hemos visto, durante un tiempo bastante largo, el rechazo para admitir las causas y las consecuencias de los cambios climáticos fue la primera reacción. Cuando el problema abandona el ámbito de las externalidades, para entrar en el de la acumulación, las perspectivas cambian. El enfoque de 
los picos de producción de la energía fósil y el crecimiento del precio del petróleo se añadieron a los daños climáticos y desembocaron en el interés dirigido a los agrocarburantes.

La opinión pública, alertada sobre el problema por los informes científicos, por las decisiones políticas y por los medios de comunicación de masas, estaba preparada para legitimar toda medida susceptible de disminuir las emisiones de $\mathrm{CO}_{2}$ en la atmósfera y de resolver la crisis energética.

De otro lado, numerosas grandes potencias mundiales, como los Estados Unidos y la Unión Europea, sin hablar de los países emergentes, tales como: China e India, se preocuparon cada vez más de su dependencia por la energía fósil del Medio Oriente o de otras "regiones inestables", en África o en América latina. Esto incitó a los Estados del Norte, pero también del Sur, a estimular el sector renovable de la energía, por una serie de medidas, que van desde los subsidios directos hasta la detaxación o la disminución de derechos de aduana.

El contexto era pues favorable a la posibilidad de inversiones rentables en las energías verdes y en particular en los agrocarburantes. De hecho, las tecnologías de la primera generación de etanol y de agrodiesel eran de punta, lo que permitía un retorno rápido de la inversión. Las investigaciones concernientes una segunda o una tercera generación (utilización de desechos vegetales y después de la celulosa, es decir la madera) estaban ya en camino, con la esperanza de obtener resultados rápidos. Además, se encontraban fuertemente financiadas por fondos públicos. Era la ocasión de promover nuevas tecnologías, monopolizadas por grupos poderosos, en particular en el dominio de los OGM.

El sector de los agrocarburantes posee, pues, numerosas facetas en el ámbito de los intereses económicos. Mientras que el caso del petróleo y del gas, las empresas públicas han tomado el comando, dejando al ámbito privado el refinamiento y la distribución, aun si ciertas empresas del Estado se encuentran a veces dominadas por el capital privado, como en el caso de Petrobras en Brasil; los carburantes por el contrario, entran directamente en el sector privado, desde la etapa de la producción. Ciertas empresas multinacionales o grandes propietarios adquieren enormes cantidades de tierra. En general son empresas locales que a primera vista parecen gozar de una cierta autonomía financiera, porque poseen estatutos jurídicos propios. Pero en realidad se encuentran con frecuencia vinculadas entre ellas por 
accionistas comunes, institucionales o personales o bien hacen parte de grupos más complejos, que los introducen en el seno del capital internacional, cuando no son simplemente el nombre local de una empresa transnacional. Es el caso de la palma oleaginosa o de la soya.

El etanol en las regionales tropicales está ligado generalmente a las grandes explotaciones azucareras de la antigua oligarquía, reconvertida al capitalismo agrario. Es el caso de Brasil o de las Filipinas. Pero hay también inversiones internacionales, sea de parte de los "hiperricos" en búsqueda de inversiones nuevas y rápidamente rentables, como Bill Gates o George Soros, con frecuencia citados, o de las multinacionales del automóvil, de la química y del agronegocio. Era importante, pues, abordar este tema de las apuestas económicas y financieras; lo que hacemos aquí tratando sucesivamente de nuevas dimensiones del agronegocio, de las inversiones privadas y públicas y de las redes internacionales del capital implicado en el dominio de los agrocarburantes.

\section{Las nuevas perspectivas del agronegocio}

Con los agrocarburantes, la agroenergía adquiere un nuevo impulso.
La producción y la distribución de los productos agrícolas habían interesado a las grandes empresas multinacionales ya desde hace más de un siglo. A ello se han añadido los productores y negociantes de semillas, sobre todo, desde el momento en que ha sido posible aplicar la genética a los sectores de la agricultura y desarrollar los OGM. La industria química ha puesto en el mercado productos fertilizantes y pesticidas para aumentar o proteger los rendimientos agrícolas. Se ha creado este vínculo con diversos sectores, ciertas sociedades, como Monsanto, por ejemplo, combinan muchas funciones.

En cuanto al desarrollo de los agrocarburantes, dos sectores nuevos se interesan a la agricultura, las sociedades petroleras y la industria del automóvil. En el primer caso, se trata de conservar los monopolios establecidos sobre los recursos energéticos; y en el segundo caso, de conservar el control de los nuevos carburantes adaptándolos al ritmo exigido por las tecnologías aplicadas a los motores. Algunos ejemplos concretos permiten comprender las múltiples implicaciones y las alianzas que se atan en torno de esta nueva actividad.

Prácticamente todas las sociedades petroleras se interesan hoy por los agrocarburantes. Se destacan los nombres de Total, en África; Shell 
que invierte en las investigaciones para la producción de etanol a partir de la celulosa, de BP, de Exxon; pero también están empresas más jóvenes, como Petrobras en Brasil; Repsol en España y en América latina; Ecopetrol en Colombia, que posee el 50\% de capital de siete empresas productoras de palma y que ha invertido 23 millones de dólares en la empresa Ecodiesel Colombia S.A. Son evidentemente las empresas del agronegocio las más concernidas por la nueva actividad. Sin embargo, un cierto número de ellas establecen vínculos estrechos con firmas petroleras o empresas de automóviles, sin mencionar los acuerdos que se establecen en el seno mismo del sector. No citaremos más que algunos casos, para ilustrar esta dinámica en curso.

Archer, Daniel y Midlan (ADM), uno de los gigantes del agronegocio ha concluido acuerdos con Cargill \& Bunge, para la producción de agrocarburantes. Estas dos grandes empresas están directamente implicadas en este dominio. Así, Cargill, empresa de Estados Unidos, posee 2,6 millones de hectáreas de soya transgenética en Paraguay. Sin duda no se trata únicamente de producir carburantes, pero la tendencia nueva privilegia este sector. La empresa de control la Central Energetica do Vale do Sapucai (Cevasa), en el Estado de
Sao Paolo, reúne los intereses de muchas multinacionales. Cargill ha igualmente construido un megapuerto para el transporte de granos de soya en Paraguay, con una capacidad de exportación de un millón de toneladas al año. Lo mismo fue en Santarem en Paraná, Brasil, por intermedio de la sociedad Cargill Agricola S.A., que es su filial brasileña. Recientemente la empresa ha perdido un proceso contra el Estado de Paraná en un asunto de control fiscal.

Bunga, igualmente, norteamericana está implicada en la exportación de azúcar y de alcohol del Brasil. Para efectos de ello compró la empresa Santa Juliana de Minas Gerais e intentó adquirir la fábrica de Vale do Rosario, la tercera en importancia del país en la producción de etanol. Con otro gran gigante, DuPont, creó una empresa local, llamada Treus, destinada a producir maíz y soya híbridos y se ha comprometido con BP para la producción de etanol, inicialmente, a partir de la caña de azúcar.

La multinacional suiza Syngenta es muy activa en América latina, en especial en el desarrollo de enzimas para el maíz híbrido (maíz 3.272). Esta empresa ha concluido un acuerdo de diez años con Diversa Corporation para la producción de enzimas transgénicos para el etanol. 
La empresa Monsanto, que con Syngeta y DuPont controla el $44 \%$ de la venta de semilla en todo el mundo, ha establecido acuerdos para la producción de biocarburantes a base de OGM; entre otros con Dow Chemical para producir semillas de maíz resistente a ocho herbicidas y con la empresa Basf para la investigación de nuevas formas de transgénicos de maíz, soya, algodón y canela: las inversiones fueron de 1,5 millones de dólares. Otro acuerdo ha sido realizado con Cargill, para conjuntamente constituir la empresa Renessen destinada también ella a producir formas transgénicas de maíz y de soya, para los agrocarburantes y para los forres. Tales alianzas tienen por finalidad de parte de Montsanto construir una estrategia de competición con Syngenta y DuPont.

Otras empresas de menor dimensión están igualmente presentes en estos sectores y no podemos dar más que algunos ejemplos. Se trata entre otras de Global Food, empresa norteamericana que se ha aliado en Brasil con la empresa Santa Elisa para constituir la Compañía Nacional de Azúcar y alcohol (CNAA), con una inversión de 2 mil millones de reales para la construcción de cuatro fábricas en Goias y Minas Gerais.

Si salimos del continente latinoamericano para abordar otros hori- zontes, podemos citar en África, a título de ejemplo, la Sociedad francesa de caucho (Sofinal, S.A.), holding cuya sede está en Luxemburgo y que posee plantaciones de palma en Liberia, en Costa de Marfil, en Indonesia, en Camerún y en Nigeria. La Sociedad de caucho de Grand Bereby (SOGB), con la ayuda de la Sociedad financiera internacional (SFI), uno de los organismos constitutivos del Banco Mundial ha invertido 6 millones de dólares para las plantaciones de palma en Costa de Marfil. La sociedad camerunesa de Palmares (Socapalm), perteneciente al grupo Boloré en Francia, ha invertido, igualmente en África, en las plantaciones de palma. En Papuasie, una empresa mixta ha sido creada, la Pacific Palm Plantation Ltda., con un $20 \%$ de participación del gobierno para la exportación de 23.000 hectáreas de palmas oleaginosas.

Empresas a la vez químicas y farmacéuticas están también interesadas en el sector de los agrocarburantes. Se trata de Bayer, de Dow Chemicals, de DuPont, que ha concluido acuerdos con BP para la distribución de etanol en Inglaterra e igualmente de Basf. Es interesante constatar hasta qué punto, las estrategias industriales se construyen a partir de intereses muy diversos. Pero hay también grupos y persona- 
lidades que ven en este sector en crecimiento una oportunidad de ganancias financieras. Es el caso de Peter Cremer Gruppe, que ha colocado 20 millones de dólares en Singapur para una refinería, que permita producir agrodiesel. Otras empresas financieras están igualmente implicadas, como Kidd and Company de los Estados Unidos, que controla la empresa Coopernavi en Brasil, Merry Linch de Stark and Och-Zit Management, fondos de inversión, activos en Brasil y de Infinity de Londres, que ha puesto capitales en cuatro fábricas productoras de etanol en Brasil. Se puede añadir Louis Dreyfus, de Francia, quien ha inyectado capitales en cuatro fábricas del grupo Travares de Melo de Pernambuco y de Tereos, igualmente francesa, con inversión en Cosan y en la Franco-Brasileira de Azúcar, dos empresas de Brasil.

Recordemos de nuevo que un cierto número de personas, muy conocidas en los medios financieros se han implicado en el sector. Se trata por ejemplo de Georg Soros, accionista de Adecoagro en Minas Gerais y en Mato Groso en Brasil o James Wolfensohn, antiguo director del Banco Mundial y administrador de Brenco (Brasil Sun Renewable Energy Company) fundada por André Philippe Reichstuk, antiguo director de Petrobras, en donde ha puesto un capital de 2 mil millones de dólares. El mismo se encuentra con Vinod Khosla, de la empresa Sun Microsystem, uno de los fundadores de Google e igualmente accionista de Brenco. Carlos Slim, el principal hombre de negocios de México y según Forbes la segunda fortuna mundial, invirtió en los agrocarburantes en Paraguay. Es necesario citar a Bill Gates, accionista de Pacific Ethanol, empresa activa en Brasil. En Europa Nord Zucker-Sud Zucker y en India, BHL, invierten asimismo en los agrocarburantes. Este género de inversiones ha comenzado a interesar también los Fondos de pensión, como lo señala el Wall Street Journal del 26 de agosto de 2006, con un verdadero peligro de inscribir dichos fondos de pensión en el dominio de la especulación de los agrocarburantes.

Como se trata de un sector de punta, con perspectivas de desarrollo ulterior, otros tipos de empresas se comprometen a su vez en este dominio. Es el caso de ciertas empresa forestales, como Stora Enso, Aracruz, Botnia en América latina. Se recordará que etanol de segunda y tercera generación tienen la intención de utilizar la celulosa, es decir productos forestales.

Horizontes completamente nuevos se abren a la creación de organismos vivos artificiales, capaces de 
producir energía. Se trata pues de rebasar la dimensión puramente general, para intentar entrar en dominios nuevos de los seres vivos, $y$ es lo que hace la empresa Sinthetic Genomics de los Estados Unidos (EcoPortalnet, 21 de septiembre de 2007).

\section{La colaboración de los pode- res públicos}

Hemos ya tenido la ocasión de señalar la intervención de los poderes públicos, nacionales e internaciones en el dominio de la producción de los agrocarburantes. No sólo actúan con los instrumentos habituales de los Estados, es decir, la desfiscalización, por ejemplo en PapuasiaNueva-Zelanda para la producción de la palma oleoginosa o en los Estados Unidos para el etanol a base de maíz, las concesiones acordadas a las empresas nacionales o internacionales, pero igualmente el co-financiamiento de la investigación y de la producción.

Así, el Estado colombiano, ha proporcionado una ayuda financiera, bajo forma de préstamo a bajas tasas de interés, a muchas empresas de palma. Es el caso, por ejemplo de Urapalma, que ha desarrollado plantaciones en la región del Chocó, a veces incluso de manera ilegal, como lo ha demostrado un tribunal del país. Es interesante notar que el apoyo a este género de plantación está integrado en el Plan Colombia, el cual financia concretamente la utilización de glifosfato, producido por Montsanto y aplicado localmente por Dyncorp, y que es un herbicida utilizado con frecuencia sin discriminación y en fuertes dosis ${ }^{8}$. El argumento de la aplicación del protocolo de Kyoto es igualmente empleado para apoyar la iniciativa de Montsanto, por medio de la Compañía Agrícola Colombiana Ltda., en particular para producir maíz transgénico, capaz de dar etanol con la tecnología M810. DuPont de Colombia goza de favores muy similares.

USAID ha invertido 700.000 dólares de fondos antidroga para financiar los palmerales en el marco del Colombian Agrobusiness Partneship Program. Este último está destinado, según su propia definición, a proporcionar su apoyo a actividades privadas con la finalidad de favorecer la producción o la transformación de 
productos agrícolas legales y rentables en regiones o en los lugares próximos de producciones ilícitas. Las empresas que se han beneficiado de esta ayuda son precisamente Uraba, Union of Palm Growers y Urapalama9.

En Papuasia-Nueva-Guinea el Banco Asiático de Desarrollo estima que este género de producción es el mejor medio de reducir la pobreza, por ello ha decidido financiarlo. En cuanto al Banco Mundial, a través del CFI, destinado a sostener el sector privado de los países pobres, financia las plantaciones de palma en Costa de Marfil. La razón dada es la multiplicación del empleo, la elevación del nivel de vida, la obtención de divisas extranjeras y el cuidado del medio ambiente. Según World Rain Forest Movement la realidad es muy diferente, tanto sobre el plano ecológico como social. Se constata pues, por el conjunto de estos ejemplos, no sólo la implicación mutua de los diversos sectores económicos interesados en el fenómeno, sino igualmente el apoyo de los poderes públicos, tanto nacionales como internacionales. Los agrocarburantes representan un territorio privilegiado, particular- mente interesante para los inversionistas en un momento de crisis financiera. Dispone de todo para lograr su éxito: tecnologías ya muy avanzadas o en pleno desarrollo, medidas estatales que requieren proporciones crecientes de combustibles de origen vegetal y un acuerdo universal sobre la necesidad de reducir la utilización de la energía fósil.

De otro lado, existen intercambios constantes entre el sistema económico y el sistema político, que hacen muy permeables las fronteras y contribuyen a reforzar el poder del primero sobre el segundo. Personalidades pasan de manera sistemática de uno a otro de estos ámbitos. Los lobbies ante los parlamentarios y gobiernos han alcanzado proporciones gigantescas. No se puede por consiguiente considerar las instituciones políticas como independientes o como un verdadero contrapeso al poder económico. La autonomía es muy relativa. Esto mismo se aplica al dominio de los agrocarburantes. Es lo que se llama en Estados Unidos el efecto de los Revolving doors (las puertas giratorias).

A título de otros ejemplos solamente, un estudio sistemático sería, 
ciertamente, aún mucho más clarificador, daremos el nombre de algunos administradores de firmas y empresas multinacionales citadas en esta obra y destacadas por Geoffrey Geuens de la Universidad de Lieja (Palme, finance et pouvoir politique, junio 2007). Así, Archer, Daniels Midland (ADM) de los Estados Unidos comprende entre sus administradores presentes o pasados las siguientes personalidades: Brian Mulroney, antiguo primer ministro de Canadá; Robert S, Strauss, ex presidente del Comité Nacional Democrático y antiguo embajador de los Estados Unidos en Rusia; John R. Block, ex secretario de agricultura de los Estados Unidos; Richard Burt (republicano), antiguo embajador de la República Federal Alemana; Andrew Young (demócrata) antiguo embajador de los Estados Unidos en las Naciones Unidas.

$\mathrm{Si}$ tomamos UNILEVER nos encontramos como administradores o antiguos administradores a Lord Brittan, antiguo vicepresidente de la Comisión Europea; la baronesa Chalker of Wallasey, parlamentaria del partido conservador $y$ antiguo ministro del Desarrollo Internacional: Wim Dik, antiguo ministro holandés del Comercio Exterior; Lord Simon of Highbury (laborista), antiguo ministro de Comercio y de la
Competitividad en Europa, antiguo consejero de Tony Blaire, pero también administrador de Suez y consejero de la Deutsche Bank, de Allianz y de la Banq Morgan Stanley internacional; Onno Ruding (Radobank), de RTL, de Pechiney y de Citybank; Claudio X. González, antiguo senador del PRI de México y antiguo consejero especial del Presidente de México, pero también administrador de Kellog, de General Electric, de Kimberly-Clark, de Banamex, de Telmex y de JP Morgan Chase; Oscar Fanjul, ex secretario general del ministerio español de Industria y de Energía y consejero de BBVA, de Ericsson y de Marsch y McLennan; Georg J. Mitchell (demócrata), antiguo líder de la mayoría senatorial de los Estados Unidos; PDG de Walt Disney y administrador de FedEx, de Xeros y de Staples.

Señalemos también BP, cuyo presidente era en el 2007 Peter Sutherland, antiguo Comisario europeo para la Competitividad y antiguo director de la OMC, miembro del Comité consultivo internacional de Coca Cola y presidente de Goldman Sachs International. La Royal Dutch / Shell por su parte tiene de vicepresidente a Lord Kerr of Kinlorchard, antiguo jefe de los servicios diplomáticos británicos y antiguo embajador de la Unión Europea en los Estados 
Unidos; Wim Kok, antiguo primer ministro de los Países Bajos; Sir Anthony Acland, antiguo subsecretario de Estado del Foreign and Commonwelth Office y antiguo embajador en los Estados Unidos. La firma BASF tuvo por administrador el vizconde Etienne Davignon, antiguo vicepresidente de la Comisión Europea y antiguo presidente de la Agencia Internacional de la Energía y entre otros, administrador de Suez, Total y Unicore. En DuPont se encuentra todavía Sean O'Keefe, antiguo director de la NASA y director adjunto al presupuesto de los Estados Unidos, igual que Goran Lindhal que fue consejero especial de Kofi Annan, secretario general de las Naciones Unidas. En Indonesia, la firma PT Austindo Nusantara Jaya, activa en la producción de palma, tiene de administradores Arifin Siregar, antiguo ministro del Comercio de Indonesia, antiguo embajador en los Estados Unidos y que fue representante de este país en el FMI y en el Banco Mundial; Adrianto Machribie, administrador de Freeport McRohan, firma americana asociada a este grupo y donde sesionan J. Benett Johnston, antiguo senador republicano; Roy J. Stapleton, antiguo secretario de Estado para la Investigación y las Informaciones y antiguo embaja- dor en Singapur, en China e Indonesia, igualmente administrador de Conoc Philips. Y también Henry Kissinger, antiguo Secretario de Estado demócrata de los Estados Unidos.

Se podría hacer también la nomenclatura en el otro sentido y revelar en las diversas administraciones, gobiernos y otras comisiones, quiénes son los miembros de grandes grupos que han sido reclutados como por ejemplo, Condolezza Rice, ex secretaria de Estado de la Administración de George W. Bush y antigua administradora de Chevron, o de Kathleen B. Cooper antigua economista en jefe de Exsson, que llega a ser subsecretaria de Comercio de los Estados Unidos.

La intención de citar todos estos nombres no es la de proponer una teoría del complot ni de poner en cuestión la integridad de personas individuales, sino, más bien, de mostrar a qué conduce una lógica y finalmente un sistema, que banaliza las diferencias y tiende a unificar los intereses. Es pues difícil establecer los límites de las competencias y de creer en la independencia de las decisiones políticas. Los contrapesos son débiles en relación al poderío de los aparatos económicos y sus lógicas. 


\section{Los agrocarburantes y la crisis alimentaria}

Las crisis de alarma no han faltado estos últimos tiempos a propósito de la crisis alimentaria. Como se sabe, ésta, esencialmente, se debe a la falta de medios para procurarse víveres y no a la falta de capacidad de la tierra para producir y nutrir su población. Recordemos que según la FAO las posibilidades de producción agrícola pueden asegurar la subsistencia de unos 12 mil millones de individuos, cuando las previsiones demográficas de las Naciones Unidas hablan de una población mundial de 9.300 millones de personas en el 2050 , probando así que la tierra dispone de recursos necesarios para nutrir todo este mundo. Ello no impide que según el Banco Mundial las necesidades se duplicarán de aquí al 2050.

Según el antiguo relator especial de la Naciones Unidas, Jean Ziegler, habrá en el mundo en el 2008 unos 854 millones de personas que sufrirán hambre a causa de la pobreza y 2 mil millones que sufrirán malnutrición. De creer al Director general de la FAO, Jacques Diouf, durante un conferencia a la Universidad de La Habana en julio de 2008, el año 2007 ha visto la cifra de personas sufriendo hambre aumentar en unos 50 millones. La misma cifra es anunciada para el 2008. Es decir, en consecuencia, que el aumento de los precios de los alimentos tuvo un efecto directo sobre el fenómeno del hambre en el mundo. Ahora bien, a parte del azúcar todos los productos alimentarios han aumentado de precio desde el inicio del siglo XXI, con serio crecimiento a partir del 2007.

Esta es la causa en muchos países a través del planeta, como en Haití y en diversos países de África (Senegal, Burkina Faso, Egipto, etcétera), de agitaciones y levantamientos contra el hambre, sin hablar de numerosas reacciones sociales en muchas otras regiones del mundo. El impacto fue evidentemente mucho más fuerte en los países pobres, que dependen casi enteramente del exterior para su alimentación. Así, según la FAO, citada por Laeticia Clavreul (Le Monde, 20 de octubre de 2007), las importaciones de cereales cuyos precios han estallado, han hecho aumentar la canasta alimenticia en un $90 \%$ en los países subdesarrollados, contra el $22 \%$ solamente en los países más ricos. Al mismo tiempo, las grandes firmas agroalimentarias constataban como explotaban sus beneficios. Así, Cargill anunciaba un beneficio en alza de un $86 \%$ para el primer trimestre del 2008 respecto al del 2007. 
¿En qué medida el desarrollo de los agrocarburantes ejerce una influencia sobre la evolución al alza de los precios de los alimentos? Los partidarios de los combustibles de origen agrícola afirman que son otros los factores que actúan, mientras que los adversarios afirman al contrario, que este factor es ciertamente una razón central. Para dilucidar este problema nos apoyaremos en el excelente estudio del economista francés Jacques Berthelot, especialista en cuestiones agrarias y que trata precisamente de la explosión de los precios agrícolas ${ }^{10}$.

Dos suertes de razones fundamentales afectan el aumento de los precios de los cereales, como lo indica este autor: aquellas concernientes a la oferta, y las causas ligadas a la demanda. Respecto de la demanda, él cita la producción creciente de agrocarburantes, que en ciertas regiones reducen el volumen de cereales disponibles para la alimentación tanto para los humanos como para los animales; el crecimiento del consumo alimentario en los países emergentes como la China, la India o el Brasil; el aumento demográfico mundial y la especulación sobre los sectores de la economía, que toman el relevo de otros sectores actualmente en crisis. Por lo que concierne a la oferta, J. Bertholet cita tres factores: las caídas de la producción debidas en particular a razones climáticas; el aumento del precio del petróleo, operando sobre el costo de los insumos (fertilizantes y pesticidas) y de los transportes y las restricciones a la exportación de países que desean asegurar su seguridad alimentaria.

Este mismo autor añade que es necesario distinguir las causas estructurales de las coyunturales. Para el primer aspecto, se puede incluir entre otros, los cambios climáticos, la falta de inversiones en el sector agrícola y el cambio progresivo del régimen alimentario en los países emergentes. Por el contrario, las causas coyunturales son, por ejemplo, malas condiciones climáticas (particularmente en Australia en 2007), la disminución de los stocks y el brusco desarrollo de los agrocarburantes, factor que evidentemente podría volverse estructural.

La respuesta del Banco Mundial a la cuestión es perentoria. Según los cálculos de sus expertos (Don Mitchell en particular), los agrocarburantes son responsables en un 
$75 \%$ de los precios de los productos alimentarios. En un sector más particular, el del maíz, según el FMI, se trata de un $70 \%$ sin hablar de los efectos indirectos que un tal aumento puede tener sobre otros cereales, los agricultores de los Estados Unidos abandonan otros cultivos por el maíz.

En este dominio, los Estados Unidos tuvieron una responsabilidad importante vista la dimensión de su producción. Un aumento del precio del maíz por causa de los agrocarburantes repercute en el curso mundial del producto, teniendo por consecuencia la inseguridad alimentaria de las poblaciones que se nutren de él. México, en particular, ha tenido la amarga experiencia de ello. En efecto, a raíz del Tratado de Libre Comercio con los Estados Unidos y el Canadá, el país se volvió un gran importador de maíz. Los precios se dispararon de tal manera que la producción de etanol a partir del maíz se revela una herejía económica no puede mantenerse más que mediante los subsidios del Estado. Las verdaderas razones de una tal situación han de ser indagadas por una parte del lado político: el deseo de disminuir la dependencia energética de los Estados Unidos, pero también del lado económico, la influencia y el poderío de los grandes grupos del agronegocio. La producción de maíz ha pasado de 607 millones de toneladas en 2006-2007 a 776 millones en 2007-2008, en su mayor parte a causa de su absorción para la producción del etanol.

En Europa la presión es también fuerte, pues para lograr el objetivo del 10\% de agrocarburantes en el 2010, para mezclar con el carburante fósil de los automóviles (hoy cuestionado incluso en el seno de la Comisión) sería necesario consagrar un $20 \%$ de tierras arables a los cultivos destinados a los agrocarburantes. Ahora bien, Europa no dispone de tierras suficientes para este fin. De ahí el interés por los países subdesarrollados, que disponen de bastantes tierras arables, las cuales podrían ser revaloradas y así responder a estas necesidades. Ciertamente, a partir del 2008 los precios volvieron a caer bruscamente poniendo de manifiesto el carácter especulativo del fenómeno, pero en relación al principio del decenio muestran siempre un aumento.

Resulta, por consiguiente, claro que si los agrocarburantes no son la causa única del aumento de los precios alimentarios, constituyen un factor importante. Si en ciertas regiones, como Brasil, por ejemplo, la disposición de tierras permite teóricamente conducir una política ali- 
mentaria conjuntamente con el desarrollo de los agrocarburantes, en los hechos las situaciones son muy diferentes. $\mathrm{Al}$ añadirse al monocultivo de la soya y del eucalipto, al de la caña de azúcar produce un desplazamiento de ciertos cultivos alimentarios y de la cría de ganado, lo que a su vez repercute en la reducción de zonas forestales. En otras regiones del mundo, sobre todo en el Sur, las consecuencias de la extensión de los monocultivos tienen una repercusión directa sobre la desaparición de los bosques. De otro lado, Jacques Bertholet ha mostrado en su estudio que la India y la China no representaban apenas un factor determinante en el aumento de los precios alimentarios, ya que hasta ahora, estos dos países han satisfecho por sí mismos sus necesidades de un consumo creciente.

Frente a esta acumulación de contradicciones y a los efectos tan poco negativos del crecimiento de los agrocarburantes, se debe interrogar sobre las razones que empujan a desarrollarlos de manera tan intensiva.

\section{Los agrocarburantes y la reproducción del capital}

Hay, evidentemente, muchas maneras de abordar el problema de los agrocarburantes, ya sea desde el punto de vista técnico o del de los consumidores. Hemos querido poner el acento en este texto sobre la función económica de esta producción y en particular sobre el papel que juega en la reproducción del capital, muy en particular en este periodo de crisis financiera y de crisis de producción. De hecho, la reflexión lleva a concluir que el brusco aumento de producción de los agrocarburantes se inscribe ante todo en la lógica del capitalismo y que es esta última, la que explica el desarrollo repentino y rápido de un sector bien preciso del sistema económico, el de la energía, que es estratégico para el conjunto de las actividades humanas

Una tal constatación no es un descubrimiento admirable, dada la hegemonía de la lógica capitalista sobre el conjunto de la economía mundial. Sin embargo, la cuestión es tanto más central cuanto que la utilización intensa de la energía se encuentra en el centro mismo del modelo de desarrollo vehiculado por el capitalismo, en momento en que se anuncia el pico de la energía fósil y cuando la conciencia del cambio climático se vuelve un problema político.

De hecho, como lo hemos visto a lo largo de este trabajo, es un doble problema, que afecta la energía fósil. En primer lugar, el agotamiento progresivo de las fuentes de energía, par- 
ticularmente, el petróleo, el gas, a más largo plazo, el carbón e incluso hoy para el recurso mineral que es el uranio. Para alguna de estas fuentes de energía, sobre todo el petróleo y el gas, la cumbre de las reservas posibles ha sido ya alcanzada y superada. Es en concreto el caso de los Estados Unidos y de ciertos países europeos. De ahí el problema de la dependencia respecto de otras regiones del mundo para la provisión de energías fósiles.

Esto constituye la preocupación fundamental de los responsables de la economía capitalista. Sin recursos energéticos nuevos y en lo inmediato sin el control de los recursos energéticos actuales, el sistema no puede reproducirse. De donde la necesidad de asegurar en primer lugar el aprovisionamiento a partir de las regiones controladas política y militarmente por Occidente y después la de rebasar rápidamente el ciclo de la energía fósil. Es aquí que los agrocarburantes adquieren su significación, como parte integrante de las energías renovables. Es evidentemente una cuestión real y objetiva, pero a la que se puede dar muchas respuestas: encontrar soluciones que respondan a la exigencia de su valor de cambio, base del sistema capitalista o al contrario preocuparse de su valor de uso, es decir la satisfacción del "bien- estar de las poblaciones". Volveremos sobre esta cuestión en las conclusiones de esta obra.

El segundo problema es el de los daños climáticos provocados por los carburantes fósiles y la urgencia de tomar medidas concernientes el medio ambiente. El capitalismo ha considerado los problemas ecológicos como externalidades, hasta el día en que la gravedad de la situación comenzó a afectar el proceso de acumulación, lo que es un fenómeno relativamente reciente, incluso en el marco de la lógica del capital. Aquí igualmente diversas respuestas son posibles: las que toman en cuenta el conjunto del ciclo energético de los agrocarburantes y de sus efectos o las que no tienen en cuenta más que el factor inmediato de su aplicación técnica al nivel de la producción energética. Antes de abordar la cuestión de la reproducción del capital más en detalle, es conveniente preguntarse cuál es la parte de los agrocarburantes en las nuevas políticas energéticas.

\section{El lugar de los agrocarburan- tes en las nuevas políticas}

La primera constatación es que los agrocarburantes son, sobre todo, utilizados para los transportes. Pero este sector no representa más que el 
$14 \%$ de la emisión de los GES (10\% para el transporte por carretera, $2 \%$ para el transporte marítimo y $2 \%$ para el transporte aéreo, estos dos últimos en fase netamente creciente). La industria interviene con un $31 \%$, el sector residencial y los servicios con un $19 \%$. Para estas últimas actividades se trata, sobre todo, de utilización de diesel, pero igualmente de electricidad proporcionada en gran parte por el carbón y la energía nuclear.

La agricultura, por su parte, interviene en un $18 \%$ de la producción de gas a efecto invernadero, y es el caso en particular de la cría de ganado, que emite unos 70 a 75 millones de toneladas de gas por año. Es pues importante recordar, que el consumo de carne, principalmente, a causa de las transformaciones alimentarias de los países emergentes, podría haber doblado en el 2050. Los transportes no intervienen más que en una parte relativamente modesta en el problema que afecta el clima, aun si no es una parte despreciable. Recordemos que en Europa y en los Estados Unidos la parte de las energías renovables en los transportes debería pasar del $20 \%$ en el año 2020. Eso significa que el $80 \%$ de la energía será todavía de origen fósil. $\mathrm{Si}$ se transforma la mitad de las tierras arables europeas para la producción de energía de origen agrario, esto no respondería más que a una parte de la necesidad prevista y probablemente apenas al aumento de la demandad de aquí al 2020.

De otra parte, el proceso completo de producción y de distribución de los agrocarburantes no resuelve el problema climático. En efecto, su rendimiento es relativamente menor y es necesario producir más para obtener el mismo resultado. Además, de manera directa o indirecta, la emisión de $\mathrm{CO}_{2}$ no parece casi ser inferior a la que procede de la energía fósil, si se toma en consideración el conjunto del ciclo de producción, de transformación y de distribución. Incluso si estos factores pueden ser mejorados por avances tecnológicos, queda bien claro que los agrocarburantes no son más que una parte minoritaria de la solución. Entonces, una vez más ¿por qué esto interesa hoy tanto al capital?

\section{Los agrocarburantes como elementos de la producción del sistema económico capita- lista a corto y mediano plazo}

Frente a los problemas climáticos, el discurso neoliberal recordémoslo, consistió en primer lugar en negar la existencia del problema o en mini- 
mizarlo. De ello resultó una deslegitimación y un desprecio del discurso científico de los climatólogos. Como en muchos otros casos de la historia del capitalismo, la reacción que siguió fue de transformar el problema en oportunidad, lo que desembocó en un discurso optimista: la ciencia y las tecnologías llegarán a encontrar las soluciones. Finalmente, le tocó el turno al discurso ecológico y también a lo que se podría llamar la "mentira verde", consistente en mostrar hasta qué punto las tecnologías industriales recientes, las mejoras introducidas en el consumo de los vehículos e incluso las nuevas mezclas de esencia o de diesel, contribuyen a la protección de la naturaleza y al mejoramiento del clima, cuando en realidad no hacen más que prolongar un consumo destructor del medio ambiente, aun si las proporciones son menores, además que una gran parte de sus ventajas son absorbidas por el aumento de las necesidades en energía.

De otro lado, la primera reacción a la disminución de las fuentes de energías fósiles fue explotar nuevas reservas, en particular en las zonas de biodiversidad y después explotar las otras fuentes de producción energética, tales como la nuclear y los agrocarburantes, todo eso con la idea de mantener el modo de consumo actual. En el transcurso de los últimos años, la investigación intensiva de nuevas fronteras para la acumulación del capital se incrementa en razón, particularmente, de las crisis de producción y financieras, y de la baja de las tasas de beneficio. Los servicios públicos fueron cada vez más privatizados, permitiendo su transformación en mercancías y la agricultura campesina se transformó en empresas capitalistas.

Cuatro grupos de empresas transnacionales operan hoy conjuntamente: los grupos petroleros, químicos, de la agrobusiness y del automóvil. Eso les permite conservar o recuperar el control de la producción y de la distribución de la energía en los dominios nuevos y así ampliar su fuente de acumulación. No se trata, en modo alguno, de un complot, sino simplemente del resultado de la lógica misma del sistema económico, que favorece los oligopolios. Muchos elementos intervienen de hecho para hacer de los agrocarburantes un elemento importante de la acumulación del capital.

\section{El control de la propiedad de la tie- rra, base de la producción}

El origen de la producción de etanol o de agrodiesel es de naturaleza vegetal. A fin de controlar el sector, el 
control de la tierra se hace de manera directa o indirecta. La primera solución consiste en la adquisición de tierras y el Brasil es un ejemplo de ello. La segunda se cumple por el control del trabajo de pequeños campesinos, que conservan sus tierras y entran, por medio de contratos, en una dependencia respecto de las grandes empresas de la agrobusiness. Es el caso de Monsanto concretamente con la introducción de los OGM, pero también de ciertas empresas de palma oleaginosa. La subsunción del trabajo de los campesinos por el capital se efectúa por mecanismos diversos: la provisión de semilla o de las plantas, la venta de los fertilizantes y pesticidas, la compra del producto y eventualmente de préstamos usureros a las familias campesinas endeudadas. En cuanto a los precios ofrecidos, corresponden apenas a reproducir el nivel de subsistencia de las poblaciones concernidas. Es lo que algunos han llamado "la captura de los pequeños agricultores". Se asiste pues a la constitución de una de las bases del sistema capitalista, el control de los elementos necesarios para la producción, sea por la adquisición directa de la propiedad sea por la sumisión total del trabajador que queda como propietario de la tierra.

\section{La explotación del trabajo}

Es principalmente en el Sur donde el nivel de explotación de los trabajadores permanece físicamente extremo. En ciertos casos, se trata de formas de esclavitud, como en muchas plantaciones de azúcar de Brasil o de Colombia. En otros casos, el trabajo es pagado a un nivel mínimo, prácticamente sin seguridad social, ni pensión. Los sindicatos son excluidos o reducidos a la ineficacia por las represiones o la corrupción. Cuando se trata de pequeños campesinos, el nivel de subsistencia es rara vez superado, sometiendo estos últimos a un régimen muy similar a la servidumbre. En cuanto al monocultivo, este elimina una parte importante del trabajo, provocando la migración hacia las ciudades y permitiendo reducir a un estricto mínimo las preocupaciones ligadas a la utilización de la mano de obra.

En resumen, la explotación máxima del trabajo es un hecho extendido y corresponde a la lógica del capital, que consiste en hacer presión sobre los diversos elementos que intervienen en el costo de la producción a fin de maximizar las ganancias y apropiarse así de la plusvalía. Los costos sociales de una tal operación no están incluidos en la contabilidad del capital y deben ser soportados 
por la colectividad o por los individuos.

\section{La producción de nuevas tecnologías de gran riesgo ecológico pero de alta rentabilidad}

Se trata en este caso de la promoción de los OGM, en particular de la soya y el maíz, con intervenciones semejantes para los árboles, el día en que la tecnología habrá permitido utilizarlos para producir energía de origen vegetal. Se conocen los riesgos de los OGM, que mejoran la rentabilidad de los vegetales e incluso de los animales, pero cuya extensión a formas de monocultivos corre el riesgo de poner en peligro numerosas especies y cuyos efectos a largo plazo no han sido verdaderamente medidos. Esta actividad está dominada por algunos gigantes de la química y del agrobusiness: Monsanto, Cargill, Bunge, Bayer, etcétera. Numerosos gobiernos han puesto frenos a la utilización de las modificaciones genéticas, pero muy frecuentemente sus esfuerzos son contrapesados ya sea por el poderío de las empresas transnacionales, o por el hecho de que las semillas son transportadas sin control posible de una región a otra, por el viento o por los insectos $\mathrm{u}$ otros animales. Es necesario añadir que este género de cultivo utiliza general- mente mucha agua y que ciertos efectos colaterales sobre los suelos en particular no son despreciables. El crecimiento de la productividad gracias a nuevas tecnologías en una coyuntura de precios al alza permite evidentemente un aumento de los beneficios, lo que entra en la lógica de la acumulación del capital.

\section{La exclusión del costo de las externa- lidades}

Como ya lo habíamos dicho, a propósito de las migraciones campesinas hacia las ciudades, una serie de costos son transferidos a la colectividad o atribuidos a los individuos. La destrucción de la biodiversidad, de los pozos de carbón, la polución del agua, la contaminación de los suelos, esterilización de los mares, comportan costos muy importantes, son contabilizados, mientras no afecten la reproducción del capital. Son las colectividades los que deben soportar a mediano y largo plazo los efectos de tales prácticas. La enorme extensión del monocultivo terminó por crear zonas de desertificación, agotar los suelos, reducir la capa freática y destruir la biodiversidad. Estos desastres naturales son el resultado directo de la eliminación de tales costos de la contabilidad de las operaciones productivas. Pero un 
día, alguien debe soportar tales efectos, incluidos los financieros. Es el caso de los Estados, en la medida que sean capaces, o sino es simplemente el bienestar de los ciudadanos que será puesto en cuestión.

Ya hemos aludido a la expulsión de los campesinos, provocando una urbanización salvaje en el conjunto de los continentes del Sur. El origen de esta última urbanización no es el desarrollo de funciones urbanas o industriales, sino esencialmente el exceso demográfico de los campos, debido no sólo al crecimiento de la población, sino sobre todo a la expulsión sistemática de los pequeños agricultores, por el desarrollo de una agricultura capitalista. Se sabe también cuales son los efectos de las migraciones forzadas en el conjunto del mundo. El muro construido en la frontera de México con los Estados Unidos y que impide a los campesinos empobrecidos de emigrar hacia el Norte es una ilustración de ello. Cada año se cuentan más muertos que durante la existencia del muro de Berlín. En Europa los cadáveres africanos que encallan en las playas de Italia o del sur de España sirven también de testimonio. Las causas pueden ser diferentes de un lugar a otro, sea la concentración sistemática de las tierras, sean los efectos de los cambios climáticos, pero el resultado es el mismo: son pueblos enteros que pagan el precio de la lógica del desarrollo económico, del que todos estos factores son "externos" al cálculo económico.

Por otra parte, la individualización de las responsabilidades es igualmente otro rasgo del pensamiento y de la práctica neoliberal. Las migraciones hacia las ciudades o hacia el extranjero son atribuidas a decisiones personales. Así, en Colombia, el presidente Uribe estima que el problema de las personas desplazadas (los migrantes interiores, en su mayor parte a causa de la concentración de las tierras) debe ser resuelto caso por caso (cuando en realidad se trata de una lógica social) en función de las decisiones administrativas y no judiciales. Esto permite encubrir las verdaderas responsabilidades, evitar de convertirlo en un problema de derecho y consagrar definitivamente la expropiación de las tierras. La individualización del problema se vuelve también un mecanismo de externalidad.

La transferencia de fondos públicos hacia intereses privados.

La producción de agrocarburantes al no ser rentable por el momento, incluso en periodo de aumento de los precios del petróleo, se requieren subsidios a la producción, desfiscalizaciones a la venta y de bajas tarifas 
aduaneras para hacerlos más competitivos con la energía fósil. Ciertamente, el aumento rápido del precio del petróleo y del gas ha disminuido un poco la importancia de las transferencias. Pero en la mayor parte de casos, la necesidad de los subsidios por parte de los poderes públicos sigue siendo importante. El análisis de las contabilidades muestra que son las grandes empresas, que monopolizan lo esencial de las ayudas de los Estados. Los agrocarburantes reproducen pues el mecanismo clásico, que se encuentra en otros dominios, en particular en el de las armas o de los subsidios a la agricultura, tanto en los Estados Unidos como en Europa. Es lo que se podría llamar un neo-keynesianismo verde.

La lógica es siempre la misma. En la medida en que los sectores no son rentables o en caso de crisis financiera, el capital recurre al Estado, que utiliza los fondos públicos para incitar las inversiones de riesgo o para salvar los capitales financieros del desastre. Los fondos públicos son el patrimonio común que, bajo pretexto de eficacia económica, se transforma entonces en bien privado, fuente de acumulación.

Es preciso agregar la importancia de las inversiones públicas para las infraestructuras necesarias para la nueva industria: las carreteras, los ferrocarriles, los puertos, los depósitos necesarios no sólo para la producción sino también para la distribución de los agrocarburantes. Gastos, todos estos considerables, son efectuados en estos dominios con frecuencia privatizados.

\section{La reproducción de la dependencia Norte-Sur}

Las necesidades principales en las nuevas fuentes de energía se sitúan en los países del Norte, a los cuales se pueden añadir hoy los países emergentes, como la China o la India. El grueso de la producción de los agrocarburantes, por el contrario, se encuentra en el Sur, que se ve llevado a soportar los costos ecológicos y sociales de tal operación. Así es como el etanol es promovido en Brasil, en Ecuador, en Argentina, en las Filipinas, mientras que el diesel está más extendido en las regiones o países tales como Colombia, Malasia, Indonesia, África Central, PapuasiaNueva Ginea. Lo más frecuente por el momento es que estas refinerías se construyen en el Norte como en España, Asturias, o en los Estados Unidos.

Es, pues, este modelo de dependencia económica que se reproduce de nuevo: los capitales del Norte al ser la 
fuente de las tomas de decisión, no toman en cuenta las externalidades del Sur, más que cuando afecten el ritmo o la importancia de las tasas de beneficios. Aunque la producción de agrocarburantes es una fuente de divisas exteriores para un cierto número de países, eso no significa automáticamente un desarrollo autónomo, ni una ventaja socialmente repartida.

En efecto, la renta agrícola, así como la del petróleo o de las minas, anima la constitución de una clase social elitista local, esencialmente, orientada hacia el exterior. Ella juega un papel intermediario entre las empresas multinacionales y la población local y no constituye realmente una burguesía nacional, dispuesta a invertir en iniciativas de producción destinada en primer lugar a la población. El modelo es principalmente exportador. Los intereses de esta elite local sirven al crecimiento de importaciones destinadas a procurarles un nivel de vida similar, e incluso superior al de las mismas clases sociales de los países industrializados. Todo lo más una clase media superior puede también gozar del aporte de los bienes adquiridos en el exterior, sin que por ello el conjunto de la población y sobre todo los más pobres vean mejorar realmente su suerte. Como en la lógica neoliberal, el Estado ha quedado amputado de numerosas funciones, en particular en la redistribución de la riqueza, las desigualdades sociales no hacen más que aumentar.

Todo esto entra en la lógica misma del sistema capitalista, que tiene todas las ventajas para desarrollar de manera intensa el poder de compra de una minoría capaz de procurarse bienes de alto valor añadido, en lugar de producir bienes ordinarios para la mayoría de la población.

\section{La especulación}

La previsión de un aumento de los precios de las producciones agrícolas bajo el efecto del crecimiento de la demanda, debida en parte a los agrocarburantes ha desencadenado de manera inmediata una serie de prácticas especulativas. El capital financiero aumenta así sus beneficios y los fondos de pensión no son ajenos. El aporte de los agrocarburantes a la economía virtual es pues apreciable. A inicios del año 2000 se ha asistido a un desplazamiento de la especulación del petróleo y de otros sectores de la economía hacia los productos alimentarios. Incluso si diversos factores han estado en el origen de este fenómeno, se comprueba que los agrocarburantes fueron uno de ellos y no de los menores. 


\section{La relegitimación del capitalismo}

Un nuevo discurso ha hecho su aparición: el de la economía verde. Casi todos los ámbitos de la producción y de la distribución se han puesto al diapasón. Una nueva hegemonía se ha construido sobre el consenso de la opinión pública, particularmente sensible hoy a los problemas de los cambios climáticos. Los sectores económicos aparecen como benefactores de la humanidad, lo que les permite una nueva legitimidad.

Es verdad que se han cumplido esfuerzos por parte de la industria para disminuir la emisión de $\mathrm{CO}_{2}, \mathrm{y}$ en otros sectores, para evitar los despilfarros. Lo cual ha tenido un efecto real y benéfico. Sin embargo, se está evidentemente muy lejos todavía. De hecho, los esfuerzos conseguidos por la industria han tenido lugar en el momento en que la emisión de GES se convertía en un costo real y ya no una simple externalidad. Era preciso actuar sobre este factor, fruto del costo de los impasses ecológicos o resultado de medidas tomadas por los Estados, en aplicación del Protocolo de Kyoto. La sanción económica de la polución se hacía una práctica corriente, y resulta menos costoso tomar por sí mismo la iniciativa de disminuir las emisiones nocivas que continuar la contaminación.
La relegitimación supone igualmente un recurso masivo a la industria de la publicidad y, por consiguiente, a los medios de comunicación social. Sumas enormes han sido gastadas para carteles publicitarios, elogiando el carácter ecológico de las empresas y de sus productos, y para hacer pasar anuncios en la prensa, radio o televisión. La creación del consenso tiene este precio. Los medios de comunicación de masas dependen para su sobrevivencia de un tal aporte financiero, lo que de una manera $u$ otra reduce su capacidad crítica respecto de la realidad del contenido de la publicidad. Todo esto entra en la lógica del capital, que también necesita de una base ideológica, sin preocuparse siempre de la adecuación entre el discurso y la realidad. Las diversas condenas de Monsanto y de muchas otras firmas por los daños al medio ambiente dan buena prueba de ello.

Del conjunto de estas consideraciones se puede concluir que la función del desarrollo de los agrocarburantes es ciertamente la del beneficio rápido, fuente segura de acumulación a corto plazo. En efecto, no hay más que una contribución nula o débil al problema del clima y sólo un aporte marginal al consumo de combustible. Unicamente una producción masiva que cubra centenas de 
millones de hectáreas podría significar un aporte sustancial a la crisis energética, y cabe esperar que las resistencias populares y políticas no lo permitan. Por el contrario, los daños colaterales y los efectos sociales negativos de los agrocarburantes son considerables. Incluso si no se trata más que de resultados económicos positivos sólo para ciertos sectores de intereses capitalistas, estos últimos poseen ramificaciones múltiples en los lugres estratégicos de la economía capitalista mundial, que se beneficia en su conjunto. La especulación es una de sus ilustraciones. La función principal del desarrollo industrial de los agrocarburantes es, por consiguiente, la reproducción y acumulación del capital a corto y mediano plazo.

\section{Los agrocarburantes y el modelo de desarrollo}

Debemos franquear todavía un paso más para entrar en una perspectiva más profunda: la del modelo mismo de desarrollo. De hecho, los avances considerables en la utilización de la energía, gracias a las fuentes fósiles, el carbón primero, y el petróleo y el gas después, construyeron las bases materiales de la utopía del Siglo de las Luces. Esta última consistía en un progreso lineal de la humanidad hacia un provenir sin límites, donde el género humano afirmaría su dominio de la naturaleza. La ciencia debía desempeñar una función clave y sus admirables aplicaciones tecnológicas permitieron duplicar estas posibilidades, gracias a las nuevas fuentes de energía.

El sistema económico capitalista desprendió la producción respecto del trabajador por intermedio de la división del trabajo y de la industrialización, haciendo del capital el elemento motor de la actividad económica. Esto permitió realizar progresos rápidos poniendo a disposición bienes y servicios, integrando la utilización cada vez más masiva de una energía barata, como factor decisivo, no sólo de la producción, sino también de la distribución. De ello resultó un verdadero modelo de desarrollo, que apartaba o marginalizaba toda otra forma de producción y que obtenía su legitimidad de su propio éxito, lo que le permitía establecer su lógica como una evidencia.

El paso masivo al petróleo a partir de la mitad del siglo XX aumentó considerablemente la productividad del trabajo y fue el origen de una mayor fluidez en la producción y distribución de bienes y servicios. Fue también el origen del desarrollo de la agricultura industrial y permitió el 
impulso del capital financiero para la explotación de la esfera monetaria y la creación de dinero bancario. E igualmente transformó los métodos militares y la manera de conducir las guerras.

El papel preponderante de la energía tuvo por efecto, frente a la doble crisis de fuentes energéticas fósiles en vía de extinción y la destrucción climática que está vinculada a ella, poner en cuestión el modelo mismo de desarrollo, con todos sus componentes, sus condiciones materiales, sus repercusiones sociales y el modo de consumo que lo caracteriza. El problema es saber hasta cuando la humanidad podrá concebir el desarrollo capitalista como su único porvenir, cuando las contradicciones se acumulan y los cuestionamientos se precisan.

Uno de los obstáculos a nuevas soluciones se sitúa en la importancia de las apuestas económicas. Estas últimas ciegan a los actores presentes, ante todo preocupados por la reproducción de un sistema que les acuerda una posición dominante, material, política y cultural, y que ha interiorizado hasta tal punto el modelo, que identifican sus intereses como si fueran el bienestar de la humanidad. Los agrocarburantes, cuya utilidad relativa no ponemos en cuestión, les permiten una fuga hacia delante. De hecho, estos últimos aparecen o son presentados como una solución, que permitirá reproducir el mismo modelo gracias al recurso a nuevos medios.

Precisamente, cuando la crisis energética y climática parece marcar de manera cada vez más clara el fin de un modelo, el imaginario es el de una continuidad. Se buscan soluciones, que no afecten de ninguna manera las relaciones de poder sobre las decisiones económicas, ni la manera de producir, ni la manera como las riquezas mundiales son repartidas, ni el modo de consumo. Y sin embargo todo indica que el ritmo de utilización de la energía no podrá ser mantenido y que las nuevas energías no conciernen más que a una parte relativamente modesta de la expansión de las necesidades en energía, tal y como son previstas.

De otro lado, los costos económicos, sociales, medioambientales y políticos de las nuevas soluciones son muy pesados y terminan por poner en duda su real eficacia para mejorar el clima y responder a las necesidades energéticas. Ciertamente no se trata de incitar a un pesimismo absoluto, ni de creer como algunos hacen que la humanidad haya inscrito en su agenda la fecha del fin de sus días, sino de mejor reconocer la realidad. De una parte, la doble crisis climática 
y energética significa el término de la ilusión de un crecimiento sin límites $y$ de otra parte las desigualdades frente a la vida han creado a escala mundial un sistema social económicos y moralmente insoportable.

La lógica de acumulación del capitalismo es incapaz de responder a estos desafíos, pues continua considerando como externalidades todo lo que no entra directamente en el cálculo del valor de cambio. El modo de producción y de distribución ligado a esta lógica no es sostenible, pues está orientado a una sobre-utilización de materias primas y de energía por una fabricación de productos desechables o de corta duración de vida, por la extensión de los transportes debido a la deslocalización y a la dispersión de los lugares de producción y por la liberalización de los intercambios que dan la ventaja a los más fuertes.

En cuanto al consumo, este se establece al interior de un modelo arrastrado por la lógica de la acumulación, es decir por el valor de cambio más que por el valor de uso. En efecto, contrariamente a la idea generalmente admitida, que el cliente es rey y que la demanda condiciona la oferta, es lo opuesto lo que se produce. El consumo está condicionado en sus prácticas por la estructura de la producción económica y por el con- junto del aparato ideológico que lo acompaña, a la vez para legitimarlo y para incitar a la compra de bienes y servicios ofrecidos por el mercado.

La ciencia y las técnicas ciertamente aportarán todavía numerosas respuestas concretas y esto es bueno. Se harán sin duda alguna importantes progresos en el curso de los próximos años en cuanto al ahorro de la energía y en la utilización de nuevas fuentes energéticas. La energía fósil barata, cuyo ciclo se termina, no había contribuido a animar la investigación y las inversiones en este campo. Hoy los proyectos se multiplican y las experiencias florecen. Pero no está ahí el problema fundamental. Es toda la filosofía del desarrollo que está en juego.

Algunos hablan de decrecimiento, término ya utilizado por el Club de Roma en el transcurso de los años sesenta y retomado por Ramón Fernando Durán, miembro de los Ecologistas en Acción, en un notable trabajo sobre el petróleo (La historia trágica del petróleo en el mundo), escrito para el Congreso petrolero mundial de Madrid (junio 2008). El autor constata el fin del ciclo de la energía fósil y la ilusión de una transición energética, pero conservando el modelo de crecimiento y de acumulación actual, para concluir que la prosecución del proyecto neoliberal 
conduce a la profundización de la crisis y a una salida inevitable por medio de la guerra.

Es pues un cambio radical el que se muestra necesario y que Durán llama "la transición pos fósil por el crecimiento", lo que debería igualmente ser todo para ventaja del clima. Más que hablar de decrecimiento, concepto difícilmente manejable en una opinión pública influenciada por el consumo contemporáneo, preferimos hablar de la substitución de un crecimiento cuantitativo por un crecimiento cualitativo. En efecto, no se trata de disminuir el bienestar, sino al contrario de favorecerlo por una mejor calidad de vida. Volveremos sobre este tema en nuestras conclusiones.

Las resistencias a la presentación de los agrocarburantes como respuesta a la doble crisis contemporánea no se han hecho esperar. La conciencia del costo social e individual de las externalidades del modelo se ha desarrollado rápidamente, a la vez en el plano ecológico como en el plano social. Una serie de movimientos han intervenido: movimientos campesinos, ecologistas, movimientos de trabajadores y progresivamente también los poderes establecidos. Los argumentos que hemos desarrollado en esta obra han sido utilizados por unos y por otros para demostrar los límites de la utilización de los agrocarburantes como medio de luchar a favor del clima y para denunciar los efectos negativos sobre el medio ambiente natural y sobre las poblaciones campesinas. Estas reacciones han llegado igualmente al nivel de ciertos gobiernos, en particular en Europa, donde un freno ha sido puesto a los primeros engouements, de manera que se pueda llevar a los gobiernos de los países miembros de la Unión a moderar su entusiasmo.

También los movimientos más radicales como el MST (Movimiento sin Tierra) de Brasil, no han adoptado posiciones excluyendo completamente la utilización de los agrocarburos. Esto ha sido confirmado por la Comisión Cramer de los Países Bajos (2006) y por el Reporte de las Naciones Unidas sobre la Energía (2007). Está claro para todo el mundo, que el ciclo de los carburantes fósiles llega a su fin y que sus efectos negativos sobre el medio ambiente son nocivos. Es preciso pues encontrar soluciones alternativas. La utilización de agrocarburantes entra en esta lógica, pero de manera mucho menos decisiva de lo que se había imaginado en un principio. Las condiciones de aceptación de la producción de agrocarburantes por los movimientos ecológicos y 
sociales pueden resumirse en cinco puntos:

- Respetar la biodiversidad, es decir, renunciar a la solución de monocultivos, para privilegiar plantaciones diversificadas, que no pongan en peligro las especies vegetales y animales existentes.

- Limitar la frontera agrícola, es decir, evitar la devastación de las selvas y más en particular las selvas originarias. Esto significa la utilización de tierras disponibles y la protección legal de pozos de carbono y de zonas de biodiversidad o de implementaciones de poblaciones indígenas.

- Respetar los suelos y las capas freáticas, lo que prohíbe la utilización masiva de fertilizantes y de pesticidas químicos, para privilegiar una agricultura orgánica.

- Promover la agricultura campesina, permitiéndole perfeccionar sus métodos de trabajo, su acceso al crédito y la comercialización de sus productos.

- Combatir el monopolio de las sociedades transnacionales.
Respetando tales parámetros, la producción de agrocarburantes estará automáticamente orientada en primer lugar hacia las necesidades de las poblaciones locales. Es de hecho posible responder a tales necesidades por una producción, que respete los cinco principios establecidos más arriba. Pero está claro que eso significa una negación radical de la lógica del capital y una sumisión de la economía a las necesidades humanas de base. Soluciones llamadas de segunda o de tercera generación podrán sin duda aumentar la parte de los carburantes en una solución de los problemas energéticos y climáticos, pero es preciso permanecer modestos en las perspectivas del futuro. La posibilidad de reducir también los excesos energéticos por parte de las poblaciones urbanas y la de utilizar ciertos espacios para una producción más intensa para las necesidades colectivas permanece evidentemente abierta, pero en los precisos límites ecológicos y sociales. Ninguna solución global se encontrará sin poner en cuestión el modelo de desarrollo contemporáneo y sin plantear soluciones alternativas. 


\section{Bibliografía}

Alternatives Sud

2006 Changements climatiques, impasses et perspectives, vol. XIII, n. 2,

Alternatives Sud

2008 Déforestation, Causes, acteurs et enjeux, vol. XV, n. 3

Atlas de I' Environnement

2007 Paris: Le Monde diplomatique

Banque mondiale

2007 Rapport sur l'Énergie, Washington

BARBAULT, R.

2006 Un éléphant dans enjeu de quille- L'Homme dans la biodiversité, Paris: Le Seuil

BARROS, V.

2004 El Cambio climático, Bogotá: Desde Abajo

BEYOU, F. et al.

2007 Le changement climatique, aubaine ou désastre?, Paris, Le eerf,

BINSWANGER H.C.

2007 Impératifs économiques et écologiques d'une politique agricole à long terme, Horizons et Débats, 7e année, n.11, 26.03.07

BERTHELOT

2008 Les causes de la flambée des prix, Paris: Société française d'Économie rurale

CAMOLIO, E.

2002 Atlas des Pôles. Questions sur un Avenir incertain, Paris: Autrement
CARIUS, A. et al.

2006 Environnement, changement climat tique et sécurité: questions scientifiques et enjeux opérationnels, Paris: INHES

CÉPEDE, M., Houtart, F. y Grond, L.

1963 Nourrir les Hommes, Paris: Office général du Livre, Bruxelles: Editions du Cep

COMEE, $A$.

2008 Christian View on Climate Change, Bruxelles

COMMISSION CREMER, Den Haag, 2006

DANAE, S. y M. Maniatis

2007 Ecosystem Service in the Congo Basin Forest, Oxford: University Press

DE LA VEGA, L.

2007 jatropha, http://www.gvepinternational.org/file/117 Ijatro pha\%20PDF-Eng.pdf.

DESEOT, M., et al.

2004 Énergie et Climat, Paris: L'Harmattan

DOHAN DELMEDIRO, A.

2007 Les Modèles du juter Climat et scenario économique: enjeux scientifiques et politiques, Paris: La Découverte

DOLIQUE, L.

Risques globaux du Développement durable: hausses pistes et vraies

solutions, Paris.

DUSSEL, E.

2004 L'éthique de la Libération, Paris: L'Harmattan 
FAO

2008 Les biocarburants: perspectives, risques et opportunités, Rome

FERRIEUX, C.

2007 "Un verdet sans appel", Science et Avenir, marzo-abril

GEORGE, S.

2005 Le rapport Lugano, Paris: Fayart GIEC

2007 Climate Change 2007, New York

GÜBITZ, G.M., Mittelbaeh,

M., Trabi, M.

1999 "Exploitation of the tropical oil seed plant Jatropha curca s L.", Bioresource Technology, n. 67, 73-82

GUDYNAS, E.

"La naturaleza frente a la Tormenta global”, ALAl, 10.10.07.

GUY

2004 Le changement climatique, Paris: UNESCO

HOUTART, F. y G. Lemercinier

1986 Energie et Culture, Paris: L'Harmattan

KUZUCUAOGHU, C. y C. Marro

2007 Sociétéshumaines et changement climatique au troisierne millénaire: une crise a-t-elle eu lieu en Mésopotamie?, Paris, Institut français d'Etudes climatologiques

LEFF, E.

"Géopolitique de la diversité et Développement durable", Altematives Sud, vol. XIII, n. 2
LYLL, M.

1997 Commerce and Economic Changes in WestAfrica - Ihe Palm Oil Trade in the Ninetheen Century, Cambridge: University Press

LOWEN, M.

2007 Censuring Science, New York: Dutton

OTIM-NAPE, G.W., A. Bwa, Baguma y J.M. Tresh

"Epidemic mosa'ic Desease in Uganda and Eforts to control it", Africanjoumal of Root and Timber Crops, 42-43

MANICORE, J.M.

2007 Combien de degrés en plus?, www. Manicom.org, février

Movimiento mundial por los Bosques Tropicales, El amargo fruto de la Palma aceitera: despojo y deforestación, Montevideo, 2001.

PELLET, J.D. y E. Pellet

2007 jaropha-curcas, le meilleur des Biocarburants, Paris: Favre

PNUD

2008 Human Development Report, 2007-2008, New York.

PERRET, B.

2008 Le Capitalisme est-il durable?, Paris: Carnet-Nord

PIMENTEL y PATRICK

2008 Bilan énergétique des agrocarburants. Politique, Agrocarburants: riques et opportunités pour le Sud-Limites d'une revolution verte, n. HS10, décembre. 
¿Qué Cooperación Internacional para qué Desarrollo?

RUDIMANN, F.

2005 Plow, Plagues and Petroleum How Human took Control of Climate? Princeton: University Press

SCHLESSINGER, S.

2008 Lenha nova para velha fomacha-A febre dos Agrocombustibles, Río de Janeiro: Fase

SCHNOCK, A.

2008 Les agrocarburants comme politique de développement: le cas du Brésil, Mémoire a l'Université Libre de Bruxelles

Semillas (Colombie), ambiental

2007 Los Agrocombustibles, una Receta para un desastre y el Hambre en el Sur, diciembre.

South Center, Food and Energy Crisis, Geneve, 2008

STERN, N.

Report on the Economy of Climatic Change, Londres, Finance Ministry
TICKEL, O.

2008 Kyoto 2 -How to manage the Global Greenhouse, Londres: Zedbooks

VAN YPERSELE, J.P.

2008 Les Changements climatiques et la politique belge de Coopération au Développement, Bruxelles, Ministère de la Coopération

VARGAS, O.R.

2007 Geopolítica en el Siglo XXI,

VEYRET, Y. Managua

2007 Dictionnaire de l'Environnement, Paris: A. Colin

VIDAL, J.W.

2007 Brazil-Civilizao suicido, Brasilia

VERNAT, P.

2007 Les Biocarburants dans le Monde, Paris: IFP World Rin Forest, Bulletins.

ZIEGLER, J.

2005 El imperio del caos, Paris: Fayart 